\title{
Does metformin exposure before ICU stay have any impact on patients' outcome? A retrospective cohort study of diabetic patients
}

\author{
Sebastien Jochmans ${ }^{1 *} \mathbb{0}$, Jean-Emmanuel Alphonsine ${ }^{2}$, Jonathan Chelly ${ }^{1}$, Ly Van Phach Vong ${ }^{3}$, Oumar Sy ${ }^{3}$,
} Nathalie Rolin ${ }^{3}$, Olivier Ellrodt ${ }^{3}$, Mehran Monchi ${ }^{1}$ and Christophe Vinsonneau ${ }^{4}$

\begin{abstract}
Background: Impact of metformin exposure before ICU stay remains controversial. Metformin is thought to induce lactic acidosis and haemodynamic instability but may reduce ICU mortality. We evaluated its influence on outcome in diabetic patients admitted in the ICU and then compared two different populations based on the presence of septic shock.

Methods: We conducted a retrospective cohort study in a 24-bed French ICU between October 2010 and December 2013, including all ICU-admitted diabetic patients.

Results: Among 635 diabetic patients admitted during the study period, 131 (21\%) were admitted with septic shock. Multivariate analysis showed no difference in hospital mortality in all metformin users (OR 0.75 [95\% Cl 0.44-1.28]; $p=0.29)$, except in the septic shock subgroup (OR 0.61;95\% Cl [0.37-0.99]; $p=0.04)$ despite higher vasopressor dosages in the first hours after shock onset. Blood lactate level was higher in metformin users than in non-metformin users in all patients $(p<0.001)$, in septic shock patients $(p<0.001)$ and in patients without kidney injury $(p<0.001)$. Metformin users did not have more septic shock from unknown aetiology $(p=0.65)$ or unknown pathogen $(p=0.99)$.

Conclusions: Metformin use before admission to ICU did not affect in-hospital mortality. However, for patients with septic shock, mortality was lower, despite worse clinical presentation on admission. Blood lactate levels were always higher with or without septic shock and indifferent of kidney function.
\end{abstract}

Keywords: Metformin, Septic shock, Diabetes, Lactic acidosis, ICU

\section{Background}

Metformin is increasingly used as an oral antidiabetic (OAD) agent, especially in patients with type 2 diabetes mellitus. Metformin inhibits hepatic glucose production, reduces intestinal glucose absorption and improves glucose metabolism [1].

Its use is associated with a reduction in cardiovascular morbidity and mortality, in comparison with insulin, other OADs or diet alone, in non-acutely ill patients

\footnotetext{
*Correspondence: sebastien.jochmans@gmail.com

1 Département de Médecine Intensive et Unité de Recherche Clinique, Groupe Hospitalier Sud lle-de-France, Hôpital de Melun, 77000 Melun, France

Full list of author information is available at the end of the article
}

$[2,3]$. It is thought to induce or worsen lactic acidosis, especially in acute renal or liver dysfunction [4]. But in a recent meta-analysis pooling 347 trials involving longrun metformin use, the authors found no case of metformin-associated lactic acidosis (MALA), as well as no difference in blood lactate level related to metformin use [5]. These results were confirmed in a large cohort of diabetic patients treated with metformin despite various metformin contraindications, in which no MALA has been described by the authors [2].

In the ICU, MALA has been described in renal, liver, pulmonary or cardiovascular chronic failure [6], and several case reports described fatal or non-fatal MALA in acute conditions. In contrast, a recent retrospective 
study in 17 Danish ICUs found that prior to admission metformin use was associated with a reduction in 30-day mortality [3].

Our main objective in this study was to evaluate the influence of pre-admission metformin use on outcome in diabetic ICU patients and in a subgroup experiencing septic shock (an acute condition known to induce lactic acidosis $[7,8])$. Secondary objectives were to assess MALA incidence and blood lactate levels in ICU patients with diabetes, treated or not by metformin, with or without septic shock.

\section{Methods}

We performed a retrospective cohort study in our Intensive Care Medicine Department between October 2010 and December 2013. The study protocol was approved by the French Intensive Care Society (FICS)-Société de Réanimation de Langue Française (SRLF) - ethical review board.

\section{Patients}

\section{Inclusion and exclusion criteria}

All patients admitted within the study period with a history of diabetes treated by insulin or oral antidiabetics were included. So-called diabetic patients treated only with diet were considered as unconfirmed diabetes and were excluded. The other exclusion criteria were as follows:

Unknown chronic antidiabetic treatment, modifications of antidiabetic treatment during the month before ICU admission and unavailable arterial blood gas sample within $4 \mathrm{~h}$ after ICU admission.

\section{Data collection}

Collected clinical features were as follows: age, sex, height, weight, Simplified Acute Physiology Score II (SAPS II), main admission cause, metformin contraindication ('Definitions' paragraph below), ICU admission biomarkers (leucocytes, platelets, haemoglobin, creatinine, C-reactive protein, bilirubin and/or INR if available), arterial blood gas samples at day 1 , all bacteriological tests, vasopressor dosages (close to the initiation even outside the ICU), urinary output and amount of intravascular input during the first $24 \mathrm{~h}$, the use of invasive ventilation and renal replacement therapy, the presence of acute respiratory distress syndrome (ARDS), ICU and hospital length of stay and vital status.

\section{Definitions}

Usual metformin contraindications (adapted from the instructions for the use of the medicinal product) were defined as:
1. Chronic respiratory failure (previous pulmonary function tests, history of acute respiratory decompensation, oxygen or non-invasive ventilation at home, sleep apnoea) and/or

2. Chronic cardiac failure (history of pulmonary oedema, left ventricular ejection fraction $<45 \%$ ) and/ or

3. Chronic renal disease (calculated creatinine clearance with Modification of Diet in Renal Disease [MDRD] $<60 \mathrm{~mL} / \mathrm{min} / 1.73 \mathrm{~m}^{2}$ ) and/or

4. Chronic liver disease (history of cirrhosis, previous INR > 1.2) and/or

5. Myocardial infarction during the previous month

Septic shock was defined according to the Surviving Sepsis Campaign definition [9]. Acute kidney injury was defined using Kidney Disease Improving Global Outcome (KDIGO) classification [10] and was considered for any stage of the classification.

\section{Statistical analysis}

Continuous variables were expressed as median [25th75th interquartile range] or mean \pm standard deviation [95\% confidence interval] (after Shapiro-Wilks test) and compared using nonparametric Mann-Whitney (or Student's $t$ test) and linear regression tests. Categorical variables were expressed as $n$ (\%) and compared using Chi-square or Fisher's exact tests. All tests were twotailed assuming alpha risk $=0.05$. All collected data were analysed in univariate analysis regarding ICU and hospital survivals. We included in forward and backward stepwise multivariate regression models as covariates all data with $p<0.1$ in univariate analysis, with stratification by metformin use. We applied these models in ICU patients and in the subgroups of septic shock and metformin users with usual contraindication. We performed a post hoc validity assessment of the regression models by receiver operating characteristic (ROC) curves, and we selected as the result the model with the best area under the curve. Results of multivariate regression test were expressed by odds ratio ( $95 \%$ confidence interval). Prognostic value of blood lactate level on mortality was tested with ROC curves (results expressed by area under the curve [AUC] $\%$ (95\% confidence interval)), sensitivity and sensibility.

Statistical analysis and graphic representations were performed with SPSS Statistics V20 software $\left(\mathrm{IBM}^{\circledR}\right.$, New York, NY, USA) and Prism 6 software (GraphPad Software Inc. ${ }^{\circledR}$, San Diego, CA, USA).

\section{Results}

Among the 3871 patients admitted in our ICU during the study period, 635 (16.4\%) were finally included (study flowchart is available in Additional file 1: Figure S1), 
including 131 (20.6\%) patients with septic shock at day 1 after ICU admission.

Metformin use before admission was found in 240 patients $(37.8 \%)$ and was similar regarding occurrence or non-occurrence of septic shock $(p=0.69)$. Ratio of metformin use in patients with one or more usual contraindications was high $(119(49.6 \%))$ with a similar rate in septic shock patients $(p=0.54)$.

\section{ICU admission and hospital stay}

The main characteristics of ICU diabetics at admission and during ICU or hospital stays are specified in Table 1 and Additional file 1: Table S1. In our study cohort, 588 (92.6\%) patients were admitted for a medical cause, mainly for acute respiratory failure (266 (41.9\%)). There was no difference between metformin users (MET) and non-metformin users (NO-MET) in the reason for admission. MET were younger with less chronic respiratory and renal failures. They had higher blood lactate level $(p<0.001)$, lower bicarbonate $(p<0.01)$ and also lower serum creatinine $(p<0.001)$ with less acute kidney injury $(p<0.001)$. Severity score (SAPS II) and need in organ support (i.e. invasive mechanical ventilation, vasopressor, renal replacement therapy) were similar. Among MET, there was no difference in lactate level between patients with or without usual contraindication $(p=0.86)$ (Additional file 1: Table S2).

The main characteristics for diabetics with septic shock at admission and during ICU or hospital stays are specified in Table 2 and Additional file 1: Tables S3 and S4. Aetiologies of shock are specified in Additional file 1: Table S3. There was no difference between MET and NO-MET regarding unknown aetiology $(p=0.65)$ and unknown pathogen $(p=0.99)$ (Additional file 1: Table S4). MET with septic shock had higher blood lactate than NO-MET at admission $(p<0.001)$ and during the first $12 \mathrm{~h}$ (Fig. 1). Bicarbonate was lower $(p<0.01)$. They also received more renal replacement therapy $(p=0.02)$, while they had less chronic renal failure and there was no significant difference in serum creatinine, $\mathrm{pH}$, day 1 urinary output or acute kidney injury occurrence. In MET, there was a linear correlation between blood lactate and serum creatinine $(\rho=0.36 ; p<0.01)$ in contrast to NO-MET $(\rho=0.09 ; p=0.41)$ (Additional file 1: Figures S2 and S3). However, lactate was even higher in MET $(p<0.001)$ with normal kidney function (MDRD creatinine clearance $>60 \mathrm{~mL} / \mathrm{min} / 1.73 \mathrm{~m}^{2}$ ).

Septic shock severity can also be evaluated by the amount of vascular filling and the dose of vasopressors. There was no difference in the number of patients with intensive vascular filling (i.e. more than $50 \mathrm{~mL} / \mathrm{kg} /$ day) between MET and NO-MET, but there was a statistical trend for higher maximal dose of noradrenaline in MET
Table 1 Cohort of ICU diabetics: main characteristics at ICU admission, during ICU stay and ICU/hospital outcome

\begin{tabular}{|c|c|c|c|}
\hline & ICU diabetics & No metformin & Metformin \\
\hline N & 635 & $395(62.2)$ & $240(37.8)$ \\
\hline Age (y) & $71[61-79]$ & $73[62.5-80]$ & $68[60-78]^{*}$ \\
\hline Men & $408(64.3)$ & $255(64.6)$ & $153(63.8)$ \\
\hline SAPS $\|$ & 39 [31-52] & $40[32-52]$ & 38 [29-51] \\
\hline $\begin{array}{l}\text { Usual metformin } \\
\text { contraindication }\end{array}$ & $387(60.9)$ & $268(67.9)$ & $119(49.6)^{*}$ \\
\hline $\begin{array}{l}\text { Chronic respiratory } \\
\text { insufficiency }\end{array}$ & $190(29.9)$ & $132(33.4)$ & $58(24.2)^{*}$ \\
\hline $\begin{array}{l}\text { Chronic cardiac } \\
\text { insufficiency }\end{array}$ & $138(21.7)$ & $92(23.3)$ & $46(19.2)$ \\
\hline Chronic liver disease & $75(11.8)$ & $49(12.4)$ & $26(10.8)$ \\
\hline $\begin{array}{l}\text { Chronic kidney } \\
\text { failure }\end{array}$ & $144(22.7)$ & $128(32.4)$ & $16(6.7)^{*}$ \\
\hline $\begin{array}{l}\text { Recent myocardial } \\
\text { infarction }\end{array}$ & $8(1.3)$ & $5(1.3)$ & $3(1.3)$ \\
\hline $\mathrm{pH}$ & $7.36[7.28-7.42]$ & $7.36[7.29-7.43]$ & $7.36[7.27-7.42]$ \\
\hline $\mathrm{PaCO}_{2}(\mathrm{mmHg})$ & $36[29-43]$ & $37[30-44]$ & 36 [28-43] \\
\hline $\mathrm{HCO}_{3}(\mathrm{mmHg})$ & $21.3[17-25.2]$ & $21.9[17.5-26]$ & $20.4[15.3-24]^{*}$ \\
\hline Lactate (mmol/L) & $1.4[0.9-2.4]$ & $1.2[0.8-2.1]$ & $1.8[1.1-3.9]^{*}$ \\
\hline INR & $1.25[1.06-1.71]$ & $1.26[1.06-1.65]$ & $1.24[1.07-1.77]$ \\
\hline Bilirubin ( $\mu \mathrm{mol} / \mathrm{L})$ & $10[7-16]$ & $10[7-16]$ & $10[7-16]$ \\
\hline $\begin{array}{l}\text { C-reactive protein } \\
(\mathrm{mg} / \mathrm{L})\end{array}$ & $34[8-115]$ & $35[8-115]$ & 32 [8-115] \\
\hline Haemoglobin (g/dL) & $11.2[9.6-13]$ & 11.1 [9.6-12.7] & 11.7 [9.7-13.4] \\
\hline Leucocytes (G/L) & $11.2[8.1-15.3]$ & $10.8[7.5-14.6]$ & 11.7 [8.4-16.3] \\
\hline Platelets (G/L) & 213 [155-277] & 207 [155-271] & 219 [157-293] \\
\hline Creatinine $(\mu \mathrm{mol} / \mathrm{L})$ & $131[85-238]$ & 153 [90-285] & $108[80-174]^{*}$ \\
\hline Acute kidney injury & $392(61.7)$ & $268(67.8)$ & $124(51.7)^{*}$ \\
\hline $\begin{array}{l}\text { Renal replacement } \\
\text { therapy }\end{array}$ & $113(17.8)$ & $72(18.2)$ & $41(17.1)$ \\
\hline Vasopressors & $229(36.1)$ & $136(34.4)$ & $93(38.8)$ \\
\hline Invasive ventilation & $230(36.2)$ & $139(35.2)$ & $91(37.9)$ \\
\hline $\begin{array}{l}\text { ICU length of stay } \\
\text { (d) }\end{array}$ & $6[3-10]$ & $6[3.5-10]$ & $6[3-9]$ \\
\hline ICU death & $117(18.4)$ & $75(19)$ & $42(17.5)$ \\
\hline $\begin{array}{l}\text { Hospital length of } \\
\text { stay }(d)\end{array}$ & $12[6-23]$ & $12[6-23]$ & $13[7-23]$ \\
\hline Hospital death & $140(22)$ & $92(23.3)$ & $48(20)$ \\
\hline
\end{tabular}

Values are $n$ (\%) or median [IQR 25th-75th]

* $p<0.05$ between metformin and no metformin

$(p=0.09)$. Vasopressor dose was significantly higher in MET the first hours after reaching criteria for septic shock (Fig. 2).

\section{Mortality and length of stay}

ICU or hospital lengths of stay as well as ICU death showed no statistically significant difference between MET and NO-MET in the cohort of diabetics and in the 
Table 2 Subgroup of ICU diabetics with septic shock: main characteristics at ICU admission, during ICU stay and ICU/hospital outcome

\begin{tabular}{|c|c|c|c|}
\hline & Septic shocks & No metformin & Metformin \\
\hline N & 131 & $79(60.3)$ & $52(39.7)$ \\
\hline Age (y) & 70 [63-78] & 71 [64-78] & $66[61-78]$ \\
\hline Men & $89(67.9)$ & $56(70.9)$ & $33(63.5)$ \\
\hline SAPS ॥ & $52[42-69]$ & $48[40-68]$ & $57[46-68]$ \\
\hline Usual metformin contraindication & $79(60.3)$ & $56(70.9)$ & $23(44.2)^{*}$ \\
\hline Chronic respiratory failure & $30(22.9)$ & $21(26.6)$ & $9(17.3)$ \\
\hline Chronic cardiac failure & $27(20.6)$ & $20(25.3)$ & $7(13.5)$ \\
\hline Chronic liver disease & $26(19.8)$ & $18(22.8)$ & $8(15.4)$ \\
\hline Chronic renal failure & $19(14.5)$ & $16(20.3)$ & $3(5.8)^{*}$ \\
\hline Recent myocardial infarction & $1(0.8)$ & $1(1.3)$ & 0 \\
\hline $\mathrm{pH}$ & $7.32[7.2-7.38]$ & $7.32[7.23-7.39]$ & $7.26[7.17-7.38]$ \\
\hline $\mathrm{PaCO}_{2}(\mathrm{mmHg})$ & 34 [27-42] & 35 [29-43] & $34[24-42]$ \\
\hline $\mathrm{HCO}_{3}(\mathrm{mmHg})$ & $18.2[13.3-22.2]$ & $19.7[14.7-24.1]$ & $15.5[10.1-19.9]^{*}$ \\
\hline Lactate (mmol/L) & $2.2[1.1-5]$ & $1.4[1-2.8]$ & $4.5[2.1-8.7]^{*}$ \\
\hline INR & $1.5[1.2-2.3]$ & $1.6[1.3-2.9]$ & $1.4[1.1-1.9]$ \\
\hline Bilirubin $(\mu \mathrm{mol} / \mathrm{L})$ & $12[8-24]$ & $13[8-26]$ & $10[8-19]$ \\
\hline C-reactive protein (mg/L) & $95[24-224]$ & $98[30-225]$ & 85 [14-212] \\
\hline Haemoglobin (g/dL) & $10.6[9.1-12.4]$ & $10.7[9.3-12.4]$ & $10.5[9.1-12.4]$ \\
\hline Leucocytes (G/L) & $12.1[8.3-19.6]$ & $11.9[8.5-19]$ & $12.9[8.4-21.6]$ \\
\hline Platelets (G/L) & 185 [119-265] & 199 [120-273] & $173[118-252]$ \\
\hline Creatinine $(\mu \mathrm{mol} / \mathrm{L})$ & $167[113-326]$ & $163[108-276]$ & $176[123-364]$ \\
\hline Urinary output day 1 (mL) & 1200 [553-2200] & 1200 [558-1925] & 1425 [443-2400] \\
\hline Number of patients with vascular filling $>50 \mathrm{~mL} / \mathrm{kg} \geq 1$ day & $76(60.3)$ & $42(58.4)$ & $34(69.4)$ \\
\hline \multicolumn{4}{|l|}{ Maximum dose of noradrenaline } \\
\hline$(\mathrm{mg} / \mathrm{h})$ & $2[1-4.3]$ & $2[1-3.5]$ & $3.5[1.3-5]^{*}$ \\
\hline$(\mu \mathrm{g} / \mathrm{kg} / \mathrm{min})$ & $0.43[0.22-0.95]$ & $0.4[0.21-0.76]$ & $0.61[0.23-1.16]$ \\
\hline \multicolumn{4}{|l|}{ Maximum dose of adrenaline } \\
\hline$(\mathrm{mg} / \mathrm{h})$ & $2.5[1.5-6]$ & $3[1.5-6.3]$ & $2.5[1.4-6]$ \\
\hline$(\mu \mathrm{g} / \mathrm{kg} / \mathrm{min})$ & $0.61[0.25-1.22]$ & $0.52[0.22-1.3]$ & $0.66[0.27-0.98]$ \\
\hline Noradrenaline duration (h) & $39[18-64]$ & $48[19-71]$ & 36 [15-59] \\
\hline Adrenaline duration (h) & 36 [9-90] & 36 [14-90] & $30[6-102]$ \\
\hline Vasopressor duration (h) & 48 [24-96] & 48 [24-97] & $36[23-72]$ \\
\hline Acute kidney injury & $104(79.4)$ & $62(78.5)$ & $42(80.8)$ \\
\hline ARDS & $48(36.6)$ & $27(34.2)$ & $21(40.4)$ \\
\hline Renal replacement therapy & $51(38.9)$ & $24(30.4)$ & $27(51.9)^{*}$ \\
\hline Invasive ventilation & $96(73.3)$ & $56(70.9)$ & $40(76.9)$ \\
\hline ICU length of stay (d) & $9[5-16]$ & $9[6-19]$ & $7[4-13]$ \\
\hline Hospital length of stay (d) & 15 [7-29] & 15 [8-29] & $16[4-26]$ \\
\hline ICU death & $51(38.9)$ & $31(39.2)$ & $20(38.5)$ \\
\hline Hospital death & $53(40.5)$ & $33(41.8)$ & $20(38.5)$ \\
\hline
\end{tabular}

Values are $n(\%)$ or median [IQR 25th-75th]

${ }^{*} p<0.05$ between metformin and no metformin

subgroup of septic shock patients. Hospital death was not significantly different in multivariate regression model analysis (OR 0.75 [0.44-1.28]; $p=0.29$ ) (Additional file 1: Table S5). In the subgroup of septic shock patients, metformin was associated with a lower mortality after multivariate analysis with odds ratio 0.61 [95\% CI $0.36-$ 0.99 ]; $p=0.049$ (Table 3).

Blood lactate levels showed a prognostic value in MET (AUC 67.3\% (95\% CI 58.3-76.4); $p=0.001$ ) and NOMET (AUC 68.6\% (61.5-75.8); $p<0.001$ ) of the cohort 


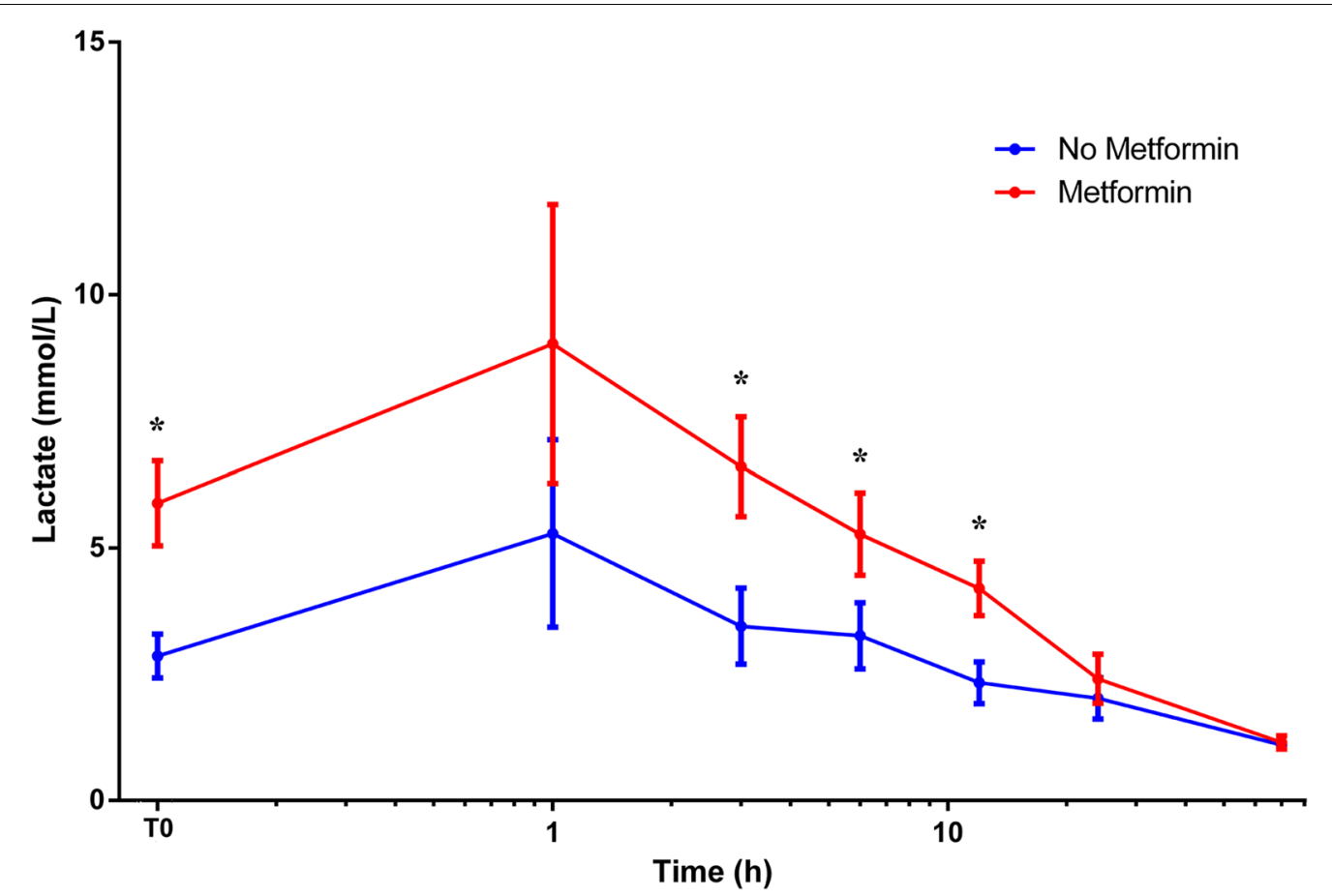

Fig. 1 Initial evolution of lactate level in ICU diabetics sustaining septic shock with or without pre-admission metformin treatment. T0: time of septic shock diagnosis. Abscissa axis is $\log 10$ scale. ${ }^{*} p<0.05$

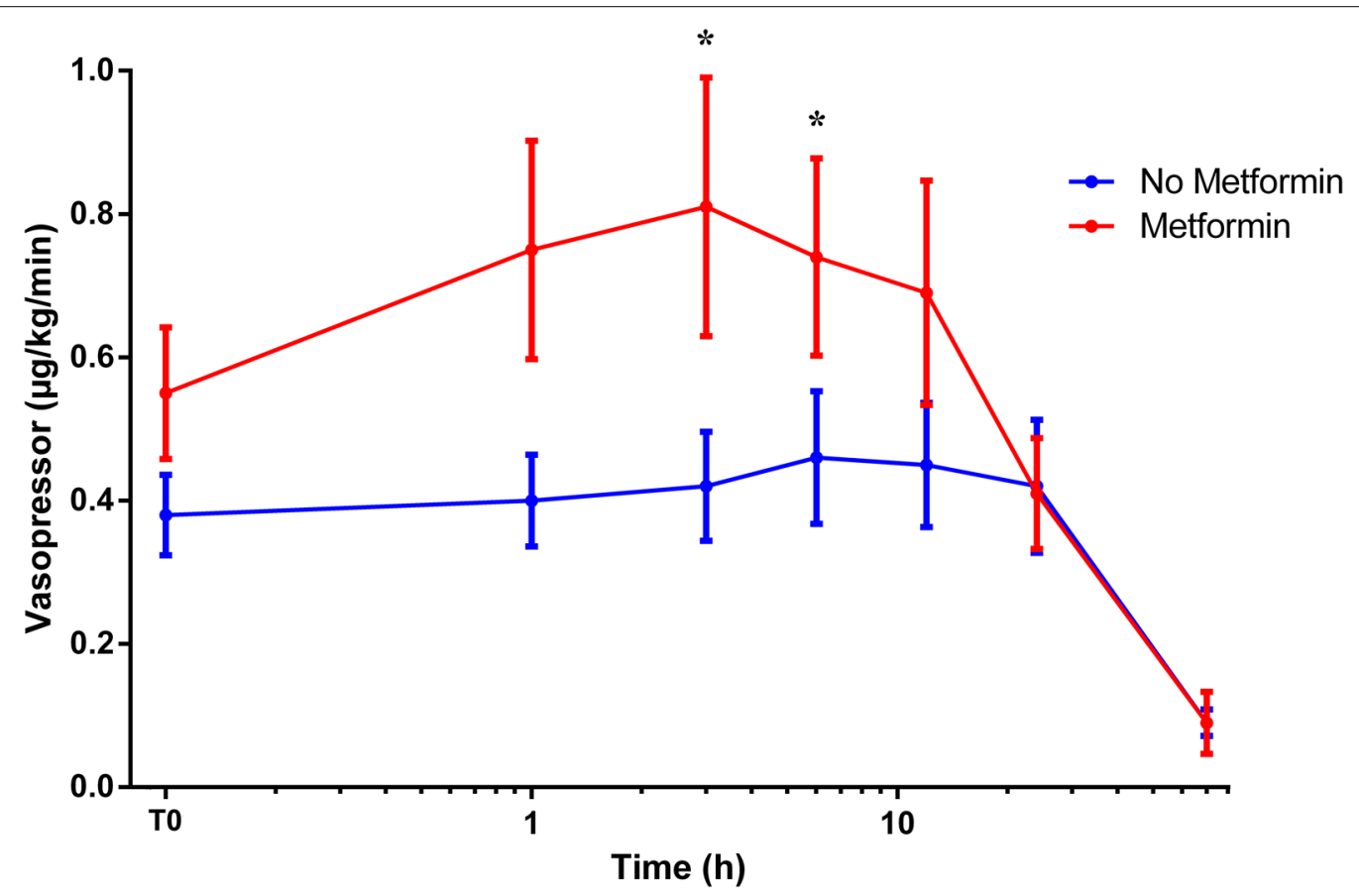

Fig. 2 Initial evolution of vasopressor dosage in ICU diabetics sustaining septic shock with or without pre-admission metformin treatment. T0: time of septic shock diagnosis. Abscissa axis is log 10 scale. ${ }^{*} p<0.05$

and also in MET (AUC 66.7\% (51.5-81.9); $p=0.05$ ) and NO-MET (AUC 65.5\% (53-78.1); $p=0.02$ ) of shocked 
Table 3 Hospital death among septic shock patients: univariate analysis and conditional forward stepwise multivariate analysis with metformin as analysis factor

\begin{tabular}{|c|c|c|c|c|c|}
\hline & Survivor & Non-survivor & $P$-univariate & Odds ratio & $P$-multivariate \\
\hline N & $80(61.1)$ & $51(38.9)$ & - & - & - \\
\hline Men & $49(61.3)$ & $40(78.4)$ & 0.055 & NS & NS \\
\hline SAPS $\|$ & $49[40-61]$ & $65[46-80]$ & 0.001 & $1.05(1.04-1.07)$ & $<0.001$ \\
\hline Metformin $(n)$ & $32(40)$ & $20(39.2)$ & 1 & $0.61(0.37-0.99)$ & 0.049 \\
\hline Lactate (mmol/L) & $1.7[1-3.9]$ & $3.2[1.4-7.1]$ & 0.003 & $1.21(1.1-1.34)$ & $<0.001$ \\
\hline $\operatorname{ARDS}(n)$ & $23(28.8)$ & $25(49)$ & 0.03 & NS & NS \\
\hline $\operatorname{RRT}(n)$ & $24(30)$ & $27(52.9)$ & 0.011 & NS & NS \\
\hline Invasive ventilation $(n)$ & $48(60)$ & $48(94.1)$ & $<0.001$ & NS & NS \\
\hline Urinary output day 1 (mL) & 1400 [675-2400] & $1030[65-1900]$ & 0.03 & NS & NS \\
\hline
\end{tabular}

$a=0.05$. Area under the curve of the multivariate model $=0.786$

$R R T$ renal replacement therapy, NS not significant

patients. But prognostic cut-off value for lactate with the highest sensitivity and specificity was higher in MET (2.15 $\mathrm{mmol} / \mathrm{L}$, sensitivity $65 \%$, specificity $61.6 \%$ ) than in NO-MET (1.35, sensitivity $66.2 \%$, specificity $61.3 \%$ ). Likewise in the subgroup of septic shock patients, cut-off values were $4.45 \mathrm{mmol} / \mathrm{L}$ (sensitivity $57.9 \%$, specificity $56.7 \%$ ) versus $1.45 \mathrm{mmol} / \mathrm{L}$ (sensitivity 58.1\%, specificity $56.2 \%)$, respectively.

Among MET, there was no significant difference in hospital death between patients with or without usual contraindication (OR 1.24 [0.48-3.2]; $p=0.66$ ) (Additional file 1: Table S6).

\section{Discussion}

In our large cohort on critically ill diabetic patients, metformin use before admission to ICU did not affect inhospital mortality; however, pre-admission metformin treatment was independently associated with a decrease in hospital mortality in the group of septic shock patients, even with an initial clinical presentation appearing more severe. Indeed, independent of kidney function, vasopressor dosages and serum lactate levels were higher during the first hours after shock onset in MET. Nevertheless, metformin did not seem to induce shock per se because there was no more septic shock from unknown aetiology or unknown pathogens in MET than in NO-MET.

A beneficial association between metformin and mortality has been already described both in selected patients with chronic heart failure [11], liver disease [12, 13], mild-to-moderate kidney failure [14] which are usual contraindications, and in ICU patients [3]. In this latter study, based on retrospective analysis of Northern Denmark database, 30-day mortality was lower in metformin users than in non-metformin users with adjusted hazard ratio $=0.8$ (95\% confidence interval $0.71-0.95)$.
Propensity-score-matched analyses yielded the same results. In our work, more than $90 \%$ were medical admissions, whereas two-thirds of the 7404 ICU patients with type 2 diabetes in Christiansen et al.s study were surgical admissions. However, no data were available concerning septic shocks, vasopressor dosages or even blood lactate levels. Mechanisms of this beneficial effect remain unclear: in ICU patients, metformin may supply higher amounts of lactate serving as an energetic carbon source and therefore is available for ischaemic tissues with glucose preservation. Metformin may also decrease cellular hypoxia of less perfused tissues by decreasing oxygen consumption.

However, clinical severity seems higher in MET. Lactate levels are significantly higher in ICU diabetics with or without septic shock (Additional file 1: Figure S4). This issue still remains controversial with studies finding no effect of metformin on lactate rate $[5,15,16]$ or, on the contrary, finding an increased lactate [17-27]. One reason for this discrepancy may be that ICU patients, unlike other patients, suffer acute stress with endogenous catecholamine release leading to increased lactate levels through adrenergic receptor stimulation. Physiological studies showed that metformin enhances lactate production and decreases oxygen consumption [23-25] by inhibiting mitochondrial chain complexes [19, 22-24, 27]. Therefore, in our study, prognostic cut-off values are higher in MET, especially when there is a septic shock, as previously found [28]. It is usually admitted that lactic acidosis in metformin users is due to a reduced renal drug clearance. Lactate and creatinine levels (and creatinine clearance) are linearly correlated in our study as previously shown $[17,18,21,26,29-31]$. But lactate levels remain higher in patients without kidney injury with metformin than without. This last issue was only previously described in case reports and one cohort 
study [26], although another study failed to find hyperlactatemia when kidney function was normal [29]. MET probably received more haemodialysis for the purpose of either correcting deeper hypobasemia or eliminating plasma metformin.

- Vasopressor dosages are higher in septic shock diabetics with pre-admission metformin. This increase in catecholamines need, which has not been previously described, is not due to acidosis per se because $\mathrm{pH}$ values are similar with or without metformin. Recent data suggest that metformin decreases adenylate cyclase activity and therefore cyclic AMP concentration [32]. The effects of vasopressors are mediated by adrenergic receptors, $\mathrm{G}$ protein and adenylate cyclase stimulations leading to an increase in cyclic AMP concentration. It is assumed that it is necessary to increase vasopressor dosages in order to obtain the same haemodynamic effect and compensate decreased adenylate cyclase activity induced by metformin. Indeed, metformin does not seem to produce sepsis-like shock because there is as much septic shock of unknown aetiology or germ in MET than in NO-MET. However, metformin actually seems to worsen the criteria usually used to assess the severity of septic shocks.

Finally, in our study, patients treated with metformin despite the presence of the usual contraindications do not have higher lactate levels. The mortality rate is not increased either. These contraindications have been challenged for several years so that metformin seems deleterious only in terminal kidney disease [33]. Our collected data did not allow us to evaluate outcome according to the intensity of each organ failure. It is possible that our patients had mainly mild-to-moderate lung, liver, heart or kidney injury that would be insufficient to worsen outcome or lactate level.

Our study is subject to certain limitations. First, it is a retrospective study, avoiding observation bias, but with selection bias due to non-inclusion of patients with missing data. Thus, we cannot determine whether metformin users are more likely to be admitted to ICU than other antidiabetics' takers, and also whether the presence of a contraindication for its use is linked to a higher rate of hospitalization. The lack of randomization of metformin therapy does not indicate whether the improvement in observed survival is due to metformin itself or whether the clinical presentation and biological characteristics of patients taking metformin appear to be 'falsely' more severe. We have included in our logistic regression model certain parameters such as lactate and bicarbonate levels, which are both influenced by the presence of metformin and most likely do not have the same prognostic value in patients previously untreated by metformin. Similarly, elevated doses of vasopressors, which are used as a criterion for poor outcome for example in the SOFA score, may not carry the same prognostic significance. Metformin blood dosage has never been performed. However, it seems linearly correlated to lactate concentration [18, 21, 31]. Lastly, comparison between MET treated or non-treated by renal replacement therapy was unfeasible because analysis would lack power and be statistically unreliable. If current scientific opinion suggests its use in metformin overdose, there is no strong proof. There is indeed a contradiction between studies finding a beneficial association between sepsis and metformin and in contrast the desire to eliminate metformin by haemodialysis. Therefore, we suggest that future studies should seek to answer two questions: Is there a benefit in giving metformin during the first hours of septic shock in diabetic patients previously untreated by metformin? Is there really a benefit in the early elimination of metformin by haemodialysis in diabetic patients with septic shock and without acute kidney injury?

\section{Conclusions}

Metformin use before admission to ICU is associated with a decrease in mortality in septic shock patients despite a worse clinical presentation on admission. Metformin users have higher lactate levels independent of kidney function and need higher vasopressor dosages during the first hours of septic shock. Metformin does not seem to induce shock per se. The presence or absence of one of the usual contraindications to taking metformin does not alter lactate levels or hospital mortality.

\section{Additional file}

Additional file 1: Figure S1. Study flowchart. Figure S2. Linear regression between blood creatinine and lactate levels in metformin users patients. Figure S3. Linear regression between blood creatinine and lactate levels in non-metformin users patients. Figure S4. Lactate levels. Table S1. Main admission pattern of ICU-admitted diabetics. Table S2. ICU-admitted diabetics with preadmission metformin treatment with or without usual metformin contraindication. Table S3. Aetiologies and germs responsible for septic shocks in ICU-diabetics. Table S4. Septic shocks without aetiology at the end of hospital stay. Table S5. Hospital death among ICU-admitted diabetic patients: univariate analysis and conditional forward stepwise multivariate analysis with metformin as analysis factor. Table S6. Hospital death among metformin patients: univariate analysis and conditional forward stepwise multivariate analysis with usual contraindication as analysis factor.

\section{Abbreviations}

AMP: adenosine monophosphate; ARDS: acute respiratory distress syndrome; AUC: area under the curve; ICU: intensive care unit; KDIGO: Kidney Disease Improving Global Outcome; MALA: metformin-associated lactic acidosis; MDRD: Modification of Diet in Renal Disease; MET: metformin users; NO-MET: non-metformin users; OAD: oral antidiabetic; ROC: receiver operating 
characteristic; RRT: renal replacement therapy; SAPS II: Simplified Acute Physiology Score II; SOFA: Sepsis-Related Organ Failure Assessment score.

\section{Authors' contributions}

SJ, JEA, CV and MM had the original idea; SJ dealt with the administrative files and authorizations; SJ, JEA, JC, LVPV, OE, OS and NR collected data; SJ and MM performed the statistical analysis; and $\mathrm{SJ}, \mathrm{JC}$ and $\mathrm{CV}$ wrote the manuscript. All authors read and approved the final manuscript.

\section{Authors' information}

First results of this study have been presented by JEA during the 44th Annual Congress of the French Intensive Care Society in Paris 2016.

\section{Author details}

1 Département de Médecine Intensive et Unité de Recherche Clinique, Groupe Hospitalier Sud Ile-de-France, Hôpital de Melun, 77000 Melun, France. ${ }^{2}$ Service de Réanimation Médicale, AP-HP, Hôpital Bicêtre, 94270 Le Kremlin-Bicêtre, France. ${ }^{3}$ Département de Médecine Intensive, Groupe Hospitalier Sud Ile-de-France, Hôpital de Melun, 77000 Melun, France. ${ }^{4}$ Service de Réanimation Polyvalente, Hôpital de Bethune, 62408 Bethune, France.

\section{Acknowledgements}

We are indebted to Charles Timoney and Sean A. Freeman for manuscript corrections.

\section{Competing interests}

SJ received fees from ResMed. JC received fees from Hamilton Medical. CV received fees from Astute Medical. The remaining authors have disclosed that they do not have any competing interest. None of these competing interests are related to the present manuscript.

\section{Availability of data and materials}

The study data will not be shared except in the case of a new study and after agreement of an ethics committee. If needed, please contact corresponding author.

\section{Consent for publication}

\section{Not applicable.}

\section{Ethics approval and consent to participate}

The study protocol was approved by the French Intensive Care Society (FICS) — Société de Réanimation de Langue Française (SRLF) —ethical review board (Reference Number CE SRLF 15-29). In this retrospective study, the requirement for patients' consent was waived.

\section{Funding}

No external source of funding.

\section{Publisher's Note}

Springer Nature remains neutral with regard to jurisdictional claims in published maps and institutional affiliations.

Received: 28 February 2017 Accepted: 4 November 2017 Published online: 02 December 2017

\section{References}

1. Gong L, Goswami S, Giacomini KM, Altman RB, Klein TE. Metformin pathways: pharmacokinetics and pharmacodynamics. Pharmacogenet Genomics. 2012;22(11):820-7.

2. Eurich DT, Weir DL, Majumdar SR, Tsuyuki RT, Johnson JA, Tjosvold L, et al. Comparative safety and effectiveness of metformin in patients with diabetes mellitus and heart failure: systematic review of observational studies involving 34,000 patients. Circ Heart Fail. 2013;6(3):395-402.

3. Christiansen CF, Johansen MB, Christensen S, O Brien JM, Tønnesen E, Sørensen HT. Preadmission metformin use and mortality among intensive care patients with diabetes: a cohort study. Crit Care. 2013;17(5):R192.
4. Arroyo D, Melero R, Panizo N, Goicoechea M, Rodríguez-Benítez P, Vinuesa SG, et al. Metformin-associated acute kidney injury and lactic acidosis. Int J Nephrol. 2011;2011:749653.

5. Salpeter SR, Greyber E, Pasternak GA, Salpeter EE. Risk of fatal and nonfatal lactic acidosis with metformin use in type 2 diabetes mellitus. Cochrane Database Syst Rev. 2010;4:CD002967.

6. Cicero AFG, Tartagni E, Ertek S. Metformin and its clinical use: new insights for an old drug in clinical practice. Arch Med Sci. 2012;8(5):907-17.

7. Kjelland $C B$, Djogovic D. The role of serum lactate in the acute care setting. J Intensive Care Med. 2010;25(5):286-300.

8. Rishu AH, Khan R, Al-Dorzi HM, Tamim HM, Al-Qahtani S, Al-Ghamdi G, et al. Even mild hyperlactatemia is associated with increased mortality in critically ill patients. Crit Care. 2013;17(5):R197.

9. Dellinger RP, Levy MM, Rhodes A, Annane D, Gerlach H, Opal SM, et al. Surviving sepsis campaign: international guidelines for management of severe sepsis and septic shock, 2012. Intensive Care Med. 2013;39(2):165-228

10. Kidney Disease: Improving Global Outcomes (KDIGO) Acute Kidney Injury Work Group. KDIGO clinical practice guideline for acute kidney injury. Kidney Int Suppl. 2012;2:1-138.

11. Romero SP, Andrey JL, Garcia-Egido A, Escobar MA, Perez V, Corzo R, et al. Metformin therapy and prognosis of patients with heart failure and newonset diabetes mellitus. A propensity-matched study in the community. Int J Cardiol. 2013;166(2):404-12.

12. Zhang X, Harmsen WS, Mettler TA, Kim WR, Roberts RO, Therneau $\mathrm{TM}$, et al. Continuation of metformin use after a diagnosis of cirrhosis significantly improves survival of patients with diabetes. Hepatology. 2014;60(6):2008-16.

13. Harris K, Smith L. Safety and efficacy of metformin in patients with type 2 diabetes mellitus and chronic hepatitis C. Ann Pharmacother. 2013:47(10):1348-52

14. Inzucchi SE, Lipska KJ, Mayo H, Bailey CJ, McGuire DK. Metformin in patients with type 2 diabetes and kidney disease: a systematic review. JAMA. 2014;312(24):2668-75.

15. Chang $\mathrm{C}-\mathrm{H}$, Sakaguchi M, Dolin P. Epidemiology of lactic acidosis in type 2 diabetes patients with metformin in Japan. Pharmacoepidemiol Drug Saf. 2016;25(10):1196-203.

16. Kamber N, Davis WA, Bruce DG, Davis TME. Metformin and lactic acidosis in an Australian community setting: the Fremantle Diabetes Study. Med J Aust 2008;188(8):446-9.

17. Sipahi S, SolakY, Acikgoz SB, Genc AB, Yildirim M, Yilmaz U, et al. Retrospective analysis of lactic acidosis-related parameters upon and after metformin discontinuation in patients with diabetes and chronic kidney disease. Int Urol Nephrol. 2016:48(8):1305-12.

18. Cucchiari D, Podestà MA, Merizzoli E, Calvetta A, Morenghi E, Angelini C, et al. Dose-related effects of metformin on acid-base balance and renal function in patients with diabetes who develop acute renal failure: a cross-sectional study. Acta Diabetol. 2016;53(4):551-8.

19. DeFronzo R, Fleming GA, Chen K, Bicsak TA. Metformin-associated lactic acidosis: current perspectives on causes and risk. Metabolism. 2016:65(2):20-9.

20. Hitchings AW, Archer JRH, Srivastava SA, Baker EH. Safety of metformin in patients with chronic obstructive pulmonary disease and type 2 diabetes mellitus. COPD. 2015;12(2):126-31

21. Adam WR, O'Brien RC. A justification for less restrictive guidelines on the use of metformin in stable chronic renal failure. Diabet Med J Br Diabet Assoc. 2014:31(9):1032-8.

22. Piel S, Ehinger JK, Elmér E, Hansson MJ. Metformin induces lactate production in peripheral blood mononuclear cells and platelets through specific mitochondrial complex I inhibition. Acta Physiol Oxf Engl. 2015;213(1):171-80

23. Protti A, Lecchi A, Fortunato F, Artoni A, Greppi N, Vecchio S, et al. Metformin overdose causes platelet mitochondrial dysfunction in humans. Crit Care. 2012;16(5):R180.

24. Protti A, Fortunato F, Monti M, Vecchio S, Gatti S, Comi GP, et al. Metformin overdose, but not lactic acidosis per se, inhibits oxygen consumption in pigs. Crit Care. 2012;16(3):R75

25. Protti A, Russo R, Tagliabue P, Vecchio S, Singer M, Rudiger A, et al. Oxygen consumption is depressed in patients with lactic acidosis due to biguanide intoxication. Crit Care. 2010;14(1):R22. 
26. Liu F, Lu J, Tang J, Li L, Lu H, Hou X, et al. Relationship of plasma creatinine and lactic acid in type 2 diabetic patients without renal dysfunction. Chin Med J (Engl). 2009;122(21):2547-53.

27. Dykens JA, Jamieson J, Marroquin L, Nadanaciva S, Billis PA, Will Y. Biguanide-induced mitochondrial dysfunction yields increased lactate production and cytotoxicity of aerobically-poised HepG2 cells and human hepatocytes in vitro. Toxicol Appl Pharmacol. 2008;233(2):203-10

28. Filho RR, Rocha LL, Corrêa TD, Pessoa CMS, Colombo G, Assuncao MSC. Blood lactate levels cutoff and mortality prediction in sepsis-time for a reappraisal? A retrospective cohort study. Shock. 2016;46(5):480-5

29. Lepelley M, Giai J, Yahiaoui N, Chanoine S, Villier C. Lactic acidosis in diabetic population: is metformin implicated? Results of a matched casecontrol study performed on the type 2 diabetes population of Grenoble Hospital University. J Diabetes Res. 2016;2016:3545914.
30. Eppenga WL, Lalmohamed A, Geerts AF, Derijks HJ, Wensing M, Egberts $A$, et al. Risk of lactic acidosis or elevated lactate concentrations in metformin users with renal impairment: a population-based cohort study. Diabetes Care. 2014;37(8):2218-24.

31. Duong JK, Furlong TJ, Roberts DM, Graham GG, Greenfield JR, Williams $\mathrm{KM}$, et al. The role of metformin in metformin-associated lactic acidosis (MALA): case series and formulation of a model of pathogenesis. Drug Saf. 2013;36(9):733-46.

32. Miller RA, Chu Q, Xie J, Foretz M, Viollet B, Birnbaum MJ. Biguanides suppress hepatic glucagon signaling by decreasing production of cyclic AMP. Nature. 2013:494(7436):256-60.

33. Hung S-C, Chang Y-K, Liu J-S, Kuo K-L, Chen Y-H, Hsu C-C, et al. Metformin use and mortality in patients with advanced chronic kidney disease: national, retrospective, observational, cohort study. Lancet Diabetes Endocrinol. 2015;3(8):605-14.

\section{Submit your manuscript to a SpringerOpen ${ }^{\circ}$ journal and benefit from:}

- Convenient online submission

- Rigorous peer review

- Open access: articles freely available online

- High visibility within the field

- Retaining the copyright to your article

Submit your next manuscript at $\boldsymbol{\nabla}$ springeropen.com 